\title{
Biologia floral e polinização artificial de pinhão-manso no norte de Minas Gerais
}

\author{
Ana Cristina Pinto Juhász ${ }^{(1)}$, Samy Pimenta(2), Bruno Oliveira Soares ${ }^{(2)}$, Danielle de Lourdes Batista Morais(3) \\ e Hudson de Oliveira Rabello(2)
}

\begin{abstract}
(1)Empresa de Pesquisa Agropecuária de Minas Gerais, Caixa Postal 12, CEP 39525-000 Nova Porteirinha, MG. E-mail: anacpj@yahoo.com.br (2)Universidade Estadual de Montes Claros, Avenida Reinaldo Viana, no 2.630, Bico da Pedra, CEP $39440-000$ Janaúba, MG. E-mail: samypimenta@bol.com.br, brunoosoares@yahoo.com.br, hudsonorabelo@gmail.com ${ }^{(3)}$ Biojan, Rua Américo Soares, no 670, Centro, CEP 39440-000 Janaúba, MG. E-mail: moraisdlb@yahoo.com.br
\end{abstract}

Resumo - O objetivo deste trabalho foi avaliar alguns aspectos da biologia floral e do sistema reprodutivo de Jatropha curcas, em Janaúba, MG. Foram registrados: o número de flores femininas e masculinas; o intervalo de abertura das flores femininas; e a formação de frutos por apomixia, autofecundação, geitonogamia e xenogamia. A proporção de flores masculinas para femininas foi de 20:1. O intervalo de abertura das flores femininas variou de um a sete dias, conforme o número delas na inflorescência. No teste de apomixia, houve formação de frutos em apenas 5\% das flores avaliadas. A percentagem de frutificação variou de 79 a $88 \%$ na autofecundação manual, na geitonogamia e na xenogamia. Na autofecundação sem a polinização manual a frutificação foi de $20 \%$, e os frutos formados foram significativamente menores, com número inferior de sementes por fruto e menor índice de velocidade de emergência. As sementes foram semelhantes às formadas por polinização natural. É possível a realização de cruzamentos controlados em pinhão-manso, e não há autoincompatibilidade nesta espécie.

Termos para indexação: Jatropha curcas, autofecundação, geitonogamia, polinização natural, xenogamia.

\section{Floral biology and artificial polinization in physic nut in the north of Minas Gerais state, Brazil}

\begin{abstract}
The aim of this work was to evaluate some aspects of the floral biology and of the reproductive system of Jatropha curcas, in Janaúba county, MG, Brazil. The number of female and male flowers, the interval between the opening of female flowers, and the formation of fruits by apomixis, self-pollination, geitonogamy and by xenogamy were registered. The ratio of male to female flowers was 20:1. The interval of opening of female flowers was of one to seven days, depending on the number of female flowers in the inflorescence. On the apomixy test, the formation of fruits occurred in only $5 \%$ of the evaluated flowers. The fruit set was between 79 and $88 \%$ through the manual self-pollination, and through the geitonogamy, and the xenogamy. In the self-pollination treatment, without the hand-pollination, the fruit set was of $20 \%$, and the fruits formed were significantly smaller, with a lesser number of seeds per fruit and lower rate of emergence. The seeds were similar to the ones formed by natural pollination. Artificial cross-pollination is possible on physic nuts, and there is no self-incompatibility within this species.
\end{abstract}

Index terms: Jatropha curcas, self-pollination, geitonogamy, natural pollination, xenogamy.

\section{Introdução}

Osprocedimentos adotados na execução dos trabalhos de melhoramento genético de espécies perenes frutíferas arbóreas dependem, fundamentalmente, do seu modo de reprodução, do conhecimento da biologia floral, inclusive a morfologia floral, do tipo de reprodução e dos aspectos relativos à polinização e à fertilização. São importantes, também, as consequências das alterações induzidas artificialmente no modo de reprodução, nos cruzamentos dirigidos e nas autofecundações. Além disso, o fruto e as sementes são economicamente as partes mais importantes da planta, o que justifica a consideração dada às flores, florescimento e frutificação (Barros et al., 1999).

O florescimento é um dos principais estágios fenológicos para a produção de óleo de Jatropha curcas, uma vez que o número de flores femininas e sua fecundação determinam quantos frutos e sementes serão desenvolvidos. O florescimento inicia-se, normalmente, após um período de dormência da planta - no Brasil, isso ocorre após o inverno, quando

Pesq. agropec. bras., Brasília, v.44, n.9, p.1073-1077, set. 2009 
a temperatura e a precipitação são reduzidas. Após a indução do florescimento, este se torna contínuo por períodos prolongados, de acordo com a disponibilidade de água no solo. A limitação de nutrientes também acarreta a paralisação do florescimento (Jongschaap et al., 2007).

Para que seja possível atender a uma determinada necessidade do programa de melhoramento da espécie (Borém, 2005), um dos recursos utilizados é a hibridação artificial, para reunir características desejáveis de diferentes genitores em um único indivíduo.

A hibridação tem por objetivo aumentar a variabilidade genética disponível das características de interesse ao programa de melhoramento genético, o que permite ao pesquisador obter sucesso com a seleção de plantas superiores. Encontradas as características de interesse, algumas vezes em genótipos menos adaptados ou em espécies silvestres, elas podem ser transferidas por meio de hibridação para os genótipos promissores em outros aspectos e gerar híbridos ou variedades superiores.

$\mathrm{Na}$ Índia, a hibridação entre várias espécies de Jatropha é realizada com o objetivo de desenvolver híbridos e variedades com teor de óleo superior e adaptadas a solos improdutivos para reflorestamento (Paramathma et al., 2007).

A geitonogamia foi testada em $J$. curcas pela polinização manual das flores femininas com pólen de flores masculinas da mesma planta, e a xenogamia, pela polinização das flores femininas com pólen de flores masculinas de outra planta da mesma espécie (Raju \& Ezradanam, 2002). Pela geitonogamia, os autores obtiveram cerca de $77 \%$ de frutos formados, e, pela xenogamia, $96 \%$. Todos os frutos xenogâmicos desenvolveram-se até a maturação. No entanto, $23 \%$ dos frutos geitonogâmicos abortaram antes de completarem total desenvolvimento. Em J. mutabilis e $J$. mollissima, Santos et al. (2005) observaram que a maioria dos frutos foram formados por xenogamia, com taxa de $80 \%$ de desenvolvimento de frutos para J. mutabilis e de $95 \%$ para J. mollissima, nas condições de caatinga, no Nordeste do Brasil. A taxa de formação de frutos por geitonogamia variou de 60 a $65 \%$. Não ocorreu apomixia em nenhuma das duas espécies. Deve-se ressaltar que a polinização de Jatropha spp. é entomófila (Heller, 1996), o que favorece a fecundação cruzada ou xenogamia.
Em frutos formados a partir de autofecundação e fecundação cruzada de $J$. curcas, a maior produção de frutos ocorreu a partir de fecundação cruzada, além de estes serem maiores e mais pesados do que aqueles produzidos por autofecundação (Abdelgadir et al., 2008). Flores com polinização cruzada tiveram maior estabelecimento de frutos do que flores autofecundadas. Flores expostas a uma ou várias visitas de abelhas produziram significativamente mais frutos do que aquelas que não receberam visitas, o que indica que as abelhas são eficazes polinizadores.

O objetivo deste trabalho foi avaliar alguns aspectos da biologia floral e do sistema reprodutivo de J. curcas, por meio da taxa de desenvolvimento de frutos, a partir do tipo de pólen adotado na realização da hibridação manual, em Janaúba, MG, para realizar hibridações controladas no programa de melhoramento desta espécie.

\section{Material e Métodos}

Os aspectos da biologia floral e do sistema reprodutivo de $J$. curcas avaliados foram: a ocorrência de apomixia; a autofecundação; a geitonogamia; a xenogamia e a percentagem de desenvolvimento de frutos na polinização natural, em inflorescências. Foi também registrado o número de flores femininas por inflorescência e a frequência de inflorescências com um determinado número de flores femininas.

A avaliação foi feita em plantas de pinhão-manso, com aproximadamente seis meses de idade, irrigadas por gotejamento, na fazenda da empresa Biojan, Janaúba, MG, de julho a outubro de 2008. Janaúba está inserida na mesorregião do norte de Minas Gerais, na área mineira do Semiárido brasileiro e na microrregião

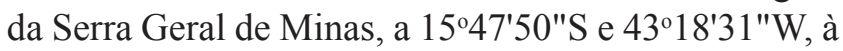
altitude média de $516 \mathrm{~m}$.

Nas avaliações, 532 flores femininas foram utilizadas, distribuídas em torno de 45 plantas de $J$. curcas; foi avaliado o total de 61 inflorescências. As inflorescências foram selecionadas de acordo com o estádio de desenvolvimento, e foram selecionadas aquelas em que as flores femininas ainda não estavam abertas.

$\mathrm{O}$ número de flores femininas variou entre 50 e 100 flores, para cada um dos sistemas reprodutivos estudados. A proporção de flores femininas, em relação às masculinas, foi avaliada em 11 inflorescências 
adicionais, uma vez que, para a realização da polinização controlada, foi necessária a eliminação de alguns botões florais em estágios iniciais de desenvolvimento, e não foi possível realizar uma correta sexagem das flores nessa fase.

Para a apomixia, as flores masculinas foram retiradas da inflorescência antes da antese e, em seguida, as flores femininas foram protegidas com sacos de organza, para evitar a entrada de insetos.

A autofecundação foi realizada pela polinização das flores femininas, com pólen de flores masculinas da mesma inflorescência. Para a caracterização da geitonogamia e xenogamia, as flores masculinas foram retiradas com o auxílio de uma pinça, ainda no estágio de botão floral. Na geitonogamia, a polinização foi realizada com o pólen da mesma planta, porém de outra inflorescência, e na xenogamia, foi utilizado o pólen de uma única planta ou, ainda, uma mistura de pólen de flores masculinas de outras plantas da mesma espécie.

O acompanhamento da abertura das flores femininas foi diário, e a polinização foi feita logo após a abertura delas. Foi registrado o período de abertura de cada inflorescência, a partir da antese da primeira, no total de 416 flores.

Para a polinização, foram coletadas flores masculinas do genitor masculino, nas primeiras horas da manhã, e a polinização manual foi realizada colocando-se as anteras da flor coletada sobre o estigma da flor feminina receptora, de forma que os grãos de pólen se soltassem e aderissem à superfície do estigma. A formação inicial dos frutos foi verificada aproximadamente 15 dias após a polinização. Foram contados o número de flores polinizadas e o número de frutos formados, e foi obtida a percentagem de desenvolvimento de frutos em cada tipo de sistema reprodutivo avaliado.

Os frutos maduros foram colhidos e pesados, as sementes foram retiradas manualmente e, após secagem natural, foram pesadas e medidas em seu comprimento e diâmetro. Nesta etapa, foi realizada a amostragem de frutos e sementes formados a partir de oito inflorescências, polinizadas por pólen de diferentes origens (relacionado ao sistema reprodutivo avaliado). Por ter havido uma variação no número de frutos e sementes formados em cada inflorescência, foi calculada a média dos frutos e sementes quanto às características avaliadas, para que cada inflorescência representasse uma repetição.

$\mathrm{O}$ experimento foi conduzido em delineamento inteiramente casualizado, com seis tratamentos (apomixia, autofecundação, geitonogamia, xenogamia com o pólen de uma única planta, xenogamia pela mistura de pólen de outras plantas e desenvolvimento de frutos por polinização natural) e oito repetições (representadas pelas inflorescências). A análise estatística foi realizada pelo programa Genes (Cruz, 2006).

A qualidade das sementes, formadas pela polinização artificial, foi avaliada por meio do índice de velocidade de emergência e da percentagem de germinação das sementes geradas. Como o número de sementes obtidas foi variável, foram utilizadas de duas a oito repetições em cada uma das avaliações. Cada repetição foi composta por 25 sementes de pinhão-manso, plantadas em areia lavada esterilizada, em bandejas de plástico. As sementes foram irrigadas com água destilada e foi contado o número de sementes germinadas e plântulas anormais, diariamente, por 15 dias.

$\mathrm{O}$ experimento foi conduzido em delineamento inteiramente casualizado, com seis tratamentos (apomixia, autofecundação, geitonogamia, xenogamia com o pólen de uma única planta, xenogamia pela mistura de pólen de outras plantas, e desenvolvimento de frutos por polinização natural) e número de repetições variável. A análise estatística foi realizada pelo programa Genes (Cruz, 2006).

\section{Resultados e Discussão}

Em Janaúba, MG, a variação do número de flores por inflorescência foi de 94 a 234, na proporção de uma flor feminina para 20 masculinas. $\mathrm{O}$ número de flores femininas por inflorescência variou de 4 a 12 . Em relação às flores masculinas, a variação foi superior, tendo sido observadas inflorescências com 87 flores e outras com até 222 flores masculinas. Em média, observou-se 7,2 flores femininas para 138,5 flores masculinas, nas 11 inflorescências avaliadas. $\mathrm{Na}$ Índia, Raju \& Ezradanam (2002) relataram que uma inflorescência pode produzir de uma a cinco flores femininas e de 25 a 93 flores masculinas, com uma média de flores femininas para masculinas de 1:29. Bhattacharya et al. (2005) descreveram uma proporção de duas a 19 flores femininas para 17 a 105 flores 
masculinas por inflorescência, também na Índia. Assim, pode-se observar que esta é uma característica muito variável, que depende do material genético, da região, do clima, dos tratos culturais, entre outros fatores.

A abertura das flores femininas não apresentou um padrão, e o intervalo de abertura floral variou com o número de flores femininas por inflorescência. $\mathrm{O}$ pico de abertura de flores femininas, em inflorescências com quatro a dez flores, foi no primeiro dia. Em inflorescências com 11 a 12 flores masculinas, a maior percentagem de abertura de flores se concentrou no segundo dia.

Todos os frutos formados por polinização artificial ou natural tiveram pleno desenvolvimento até a maturação, e não houve abortamento durante o processo de desenvolvimento dos frutos. Raju \& Ezradanam (2002) observaram que os frutos xenogâmicos desenvolveram-se até a maturação, porém $23 \%$ dos frutos geitonogâmicos abortaram antes de completar total desenvolvimento, diferentemente dos resultados obtidos no presente trabalho.

A taxa de apomixia foi de apenas 5\%, inferior à taxa relatada por Bhattacharya et al. (2005), que estimaram cerca de $32 \%$ de apomixia em $J$. curcas na Índia. $\mathrm{Na}$ China, Chang-Wei et al. (2007) também observaram a ocorrência de formação de frutos por apomixia em $J$. curcas. Em outras espécies de Jatropha, como em J. mutabilis e $J$. mollissima, não foi observada a ocorrência de apomixia (Santos et al., 2005).

Todas as sementes produzidas por polinização artificial ou natural tiveram alta percentagem de germinação, de 94 a 99\%, não tendo havido diferença significativa entre os diferentes tipos de polinização (Tabela 1). Na autofecundação sem a polinização manual, houve redução significativa no índice de velocidade de emergência (aproximadamente de 50\%) em relação aos outros tipos de polinização.
$\mathrm{Na}$ autofecundação manual, $85 \%$ das flores femininas polinizadas manualmente produziram frutos. $\mathrm{O}$ peso e o tamanho das sementes e o número médio de sementes por fruto não diferiram significativamente daquelas geradas por polinização natural (Tabela 1). No entanto, Abdelgadir et al. (2008) verificaram que na África, comparativamente, houve maior produção de frutos a partir de fecundação cruzada, maiores e mais pesados do que aqueles produzidos por autofecundação.

Os frutos e sementes formados por geitonogamia não diferiram daqueles formados por autofecundação, e apenas $79 \%$ das flores femininas polinizadas produziram frutos. Raju \& Ezradanam (2002) observaram taxa de formação de frutos semelhante, por geitonogamia (77\%). Em J. mutabilis e J. mollissima, Santos et al. (2005) observaram que a taxa de desenvolvimento de frutos por geitonogamia variou de 60 a $65 \%$, um pouco inferior à taxa observada para J. curcas.

Apesar da formação de frutos normais a partir da autofecundação, as chances de que esse fato ocorra na natureza são pequenas, pois raramente são encontradas flores femininas e masculinas abertas, concomitantemente, numa mesma inflorescência. A avaliação da autofecundação "natural”, sem polinização manual, comprova esta observação, uma vez que, na ausência de insetos polinizadores, apenas $20 \%$ das flores femininas desenvolveram frutos. Os frutos formados foram significativamente mais leves, com número de sementes por fruto inferior, com inferiores comprimento e largura de sementes (Tabela 1), e sementes com significativa redução no índice de velocidade de emergência, em relação aos outros tipos de polinização.

$\mathrm{Na}$ xenogamia, houve maior percentagem de formação de frutos nas flores polinizadas pela mistura de pólen $(88 \%)$, em relação àquelas polinizadas por um único genitor masculino (80\%). Raju \& Ezradanam (2002) relataram taxa de formação de frutos de $96 \%$ na

Tabela 1. Peso médio de frutos (PMF), peso médio de semente (PMS), número médio de sementes por fruto (NMSF), comprimento de semente (CS), largura de semente (LS), percentagem de germinação (G) e índice de velocidade de emergência (IVE), na caracterização do sistema reprodutivo de Jatropha curcas, em Janaúba, MG, de julho a outubro de $2008^{(1)}$.

\begin{tabular}{|c|c|c|c|c|c|c|c|}
\hline Tratamento & PMF (g) & PMS (g) & NMSF & $\mathrm{CS}(\mathrm{mm})$ & LS (mm) & G (\%) & IVE (\%) \\
\hline Autofecundação manual & $2,94 \mathrm{ab}$ & $0,68 \mathrm{a}$ & $2,71 \mathrm{ab}$ & $17,40 \mathrm{ab}$ & $10,41 \mathrm{a}$ & $96,00 \mathrm{a}$ & $21,72 \mathrm{a}$ \\
\hline Geitonogamia & $2,91 \mathrm{ab}$ & $0,67 \mathrm{a}$ & $2,72 \mathrm{ab}$ & $17,01 \mathrm{bc}$ & $10,42 \mathrm{a}$ & $99,20 \mathrm{a}$ & $20,25 \mathrm{a}$ \\
\hline Xenogamia $^{(a)}$ & $2,55 \mathrm{~b}$ & $0,69 \mathrm{a}$ & $2,29 b$ & $17,27 \mathrm{ab}$ & $10,39 \mathrm{a}$ & $97,60 \mathrm{a}$ & $19,72 \mathrm{a}$ \\
\hline Xenogamia $^{(b)}$ & $2,88 \mathrm{ab}$ & $0,67 \mathrm{a}$ & $2,70 \mathrm{ab}$ & $16,93 b c$ & $10,45 \mathrm{a}$ & $94,80 \mathrm{a}$ & $18,31 \mathrm{ab}$ \\
\hline Autofecundação "natural" & $1,82 \mathrm{c}$ & $0,65 \mathrm{a}$ & $1,54 \mathrm{c}$ & $16,78 \mathrm{c}$ & $9,87 \mathrm{~b}$ & $94,00 \mathrm{a}$ & $11,84 \mathrm{~b}$ \\
\hline Polinização natural & $3,14 \mathrm{a}$ & $0,69 \mathrm{a}$ & $2,93 \mathrm{a}$ & $17,56 \mathrm{a}$ & $10,71 \mathrm{a}$ & $99,00 \mathrm{a}$ & $21,26 \mathrm{a}$ \\
\hline
\end{tabular}

${ }^{(1)}$ Médias seguidas por letras iguais, nas colunas, não diferem entre si pelo teste de Tukey, a 5\% de probabilidade. Xenogamia ${ }^{(\mathrm{a})}$ : utilizado o polén de uma única planta, na polinização; Xenogamia ${ }^{(b)}$ : utilizada uma mistura de pólen de outras plantas. 
avaliação da xenogamia, valores mais próximos aos de polinização natural.

Em outras duas espécies de Jatropha, Santos et al. (2005) observaram que a maioria dos frutos foram formados por xenogamia, com taxa de $80 \%$ para J. mutabilis e de $95 \%$ para J. mollissima, em condições de caatinga, no Nordeste do Brasil.

No pinhão-manso, apesar de ser possível realizar a autofecundação e ocorrer o desenvolvimento de frutos por geitonogamia, deve-se ressaltar que prevalece a formação de frutos por xenogamia, uma vez que não há um sincronismo na abertura de flores femininas e masculinas na mesma inflorescência. Geralmente, as flores masculinas se abrem antes das femininas (Raju \& Ezradanam, 2002; Chang-Wei et al., 2007; Dnissa \& Paramathma, 2007). Em Nova Porteirinha, MG, ocorre muitas vezes o inverso, em que algumas flores femininas desabrocham antes que as masculinas se abram (Saturnino et al., 2005). Este padrão desuniforme de abertura das flores masculinas e femininas favorece a fecundação cruzada ou xenogamia (Heller, 1996; Chang-Wei et al., 2007).

\section{Conclusões}

1. É possível a realização da polinização artificial em pinhão-manso.

2. Ocorre alta percentagem de formação de frutos em pinhão-manso por autofecundação, geitonogamia e xenogamia, por meio de polinização artificial das flores.

3. A polinização artificial não altera o peso e nem a percentagem de geminação das sementes, em relação àquelas formadas por polinização natural.

\section{Agradecimentos}

À empresa Biojan, por ceder a área de produção comercial de pinhão-manso para a experimentação; a Danúbia Aparecida Costa Nobre, aluna de graduação da Universidade Estadual de Montes Claros, pelo auxílio na avaliação dos frutos e sementes.

\section{Referências}

ABDELGADIR, H.A.; JOHNSON, S.D.; VAN STADEN, J. Approaches to improve seed production of Jatropha curcas L. South African Journal of Botany, v.74, p.359, 2008.

BARROS,L.M.;PAIVA,J.R.;CRISÓSTOMO,J.R.;CAVALCANTI, J.J. Hibridação em caju. In: BORÉM, A. Hibridação artificial de plantas. Viçosa: UFV, 1999. p.191-220.

BHATTACHARYA, A.; DATTA, K.; DATTA, S.K. Floral biology, floral resource constraints and pollination limitation in Jatropha curcas L. Pakistan Journal of Biological Sciences, v.8, p.456-460, 2005.

BORÉM, A. Melhoramento de plantas. 4.ed. Viçosa: UFV, 2005. $525 \mathrm{p}$.

CHANG-WEI, L.; KUN, L.; YOU, C.; YOUNG-YU, S. Floral display and breeding system of Jatropha curcas L. Forestry Studies in China, v.9, p.114-119, 2007.

CRUZ, C.D. Programa GENES: biometria. Viçosa: UFV, 2006. 382 p.

DNISSA, K.U.; PARAMATHMA, M. Studies on pollen viability and stigma receptivity in Jatropha species. In: PARAMATHMA, M.; VENKATACHALAM, P.; SAMPATHRAJAN, A. Jatropha improvement, management and production of biodiesel. Coimbatore: Tamil Nadu Agricultural University, 2007. p.85-95.

HELLER, J. Physic nut. Jatropha curcas L.: promoting the conservation and use of underutilized and neglected crops. Rome: International Plant Genetic Resources Institute, 1996. 66p.

JONGSCHAAP, R.E.E.; CORRÉ, W.J.; BINDRABAN, P.S.; BRANDENBURG, W.A. Claims and facts on Jatropha curcas $L$. Wageningen: Plant Research International, 2007. 42p.

PARAMATHMA, M.; UMA MAHESWARI, D.; PREMALATHA, M.; JUDE SUDHAGAR, R. Hybrid breeding in Jatropha. In: PARAMATHMA, M.; VENKATACHALAM, P.; SAMPATHRAJAN, A. Jatropha improvement, management and production of biodiesel. Coimbatore: Tamil Nadu Agricultural University, 2007. p.41-46.

RAJU, A.J.S.; EZRADANAM, V. Pollination ecology and fruiting behaviour in a monoecious species, Jatropha curcas L. (Euphorbiaceae). Current Science, v.83, p.1395-1398, 2002.

SANTOS, M.J.; MACHADO, I.C.; LOPES, A.V. Biologia reprodutiva de duas espécies de Jatropha L. (Euphorbiaceae) em caatinga, Nordeste do Brasil. Revista Brasileira de Botânica, v.28, p.361-373, 2005.

SATURNINO, H.M.; PACHECO, D.D.; KAKIDA, J.; TOMINAGA, N.; GONÇALVES, N.P. Cultura do pinhão-manso (Jatropha curcas L.). Informe Agropecuário, v.26, p.44-78, 2005.

Recebido em 26 de março de 2009 e aprovado em 24 de agosto de 2009 